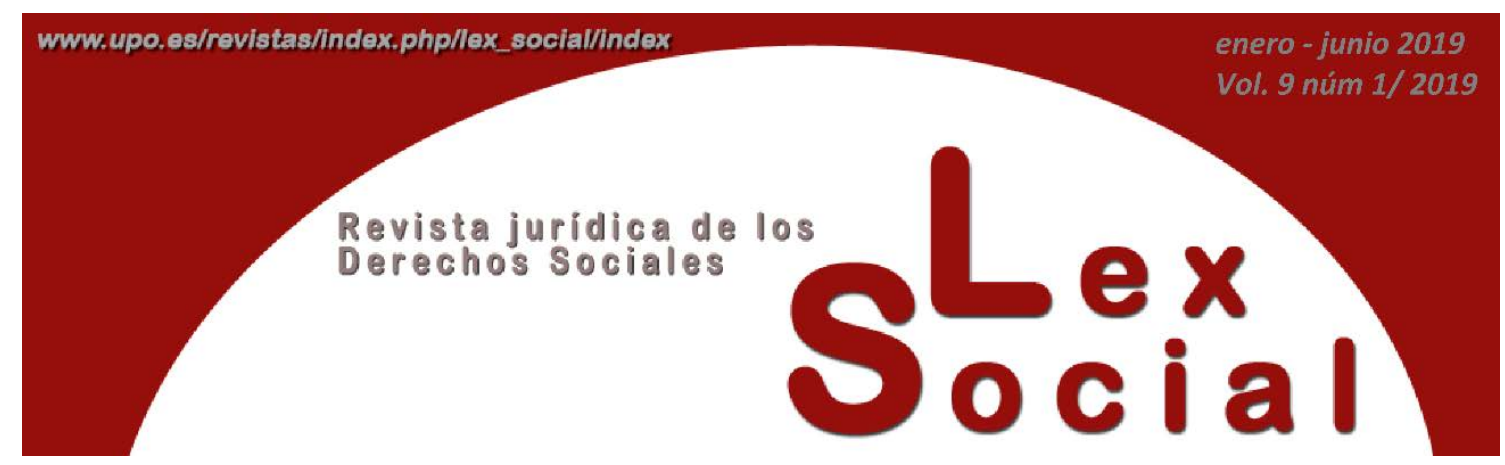

\title{
DEPENDENCIA Y DERECHO A LOS CUIDADOS DESDE UNA PERSPECTIVA DE GÉNERO
}

\section{DEPENDENCY AND RIGHT TO BE CARED FROM A GENDER PERSPECTIVE}

MARÍA HOLGADO GONZÁLEZ

Profesora Titular de Derecho Constitucional

Universidad Pablo de Olavide

Artículo recibido el 12 de marzo de 2019

Artículo aceptado el 21 de marzo de 2019

\section{RESUMEN:}

La Ley 39/2006, de 14 de diciembre, de Promoción de la Autonomía Personal y Atención a las Personas en Situación de Dependencia consagró un nuevo derecho social, derecho subjetivo directamente ejercitable por las personas en situación de dependencia, a contar con los medios necesarios que garantizaran su autonomía. Tras más de doce años en vigor, se puede hacer balance de los logros acometidos por la ley y de los desafíos que aún deben afrontarse en este ámbito en relación con la consecución de la igualdad real y efectiva y la participación en la vida social de las personas en situación de dependencia, teniendo presente el impacto de género que una materia como la de los cuidados tiene en nuestra sociedad.

Palabras Clave: dependencia, derecho a la autonomía, derecho a los cuidados, igualdad y género 


\begin{abstract}
Act 39/2006, of December 14th, of Promotion of the Personal Autonomy and Care for Dependent Persons consecrated a new social right, self-executing subjective right for people in situation of dependency to have the necessary means that guarantee their personal autonomy. After more than twelve years of applicability, it's possible to take stock of the achievements made by the law and the challenges that still have to be faced in this subject. We have also to consider the impact of gender that care has on our society in relation to real and effective equality and participation in the social life of dependent persons.
\end{abstract}

KEYWORDS: dependency, right to personal autonomy, right to be cared, equality and gender

SUMARIO:

1. La dependencia, un asunto de carácter público.

2. El cuidado como derecho social fundamental.

3. La consagración de un derecho subjetivo a la autonomía en la Ley de Dependencia.

Balance de doce años de vigencia.

4. Recapitulación.

5. Bibliografía

\title{
1. LA DEPENDENCIA, UN ASUNTO DE CARÁCTER PÚBLICO
}

¿Puede una sociedad proclamar como valores fundamentales la dignidad humana, la igualdad y la libertad y a la vez desentenderse de los problemas de las personas que tienen graves dificultades para desenvolverse por sí solas en las tareas básicas de su vida cotidiana?

Un Estado democrático que propugne la igualdad real y efectiva de las personas no puede dejar de atender esta realidad. De hacerlo, no sólo estaría condenando al desamparo a las personas en situación de dependencia sino también abandonando en una situación de clara desigualdad a quienes moralmente se sienten obligados a ello y solidariamente se dedican 
a su intenso y duradero cuidado, con el consiguiente menoscabo de sus oportunidades y desarrollo personal.

La situación de dependencia afecta tanto a las personas que la sufren directamente -por no poder valerse por sí mismas y precisar del necesario auxilio de otra persona para las tareas más básicas-, como al estrecho círculo familiar -circunscrito la mayoría de las veces a las mujeres- que asume ese apoyo y cuidado. La actuación o inhibición del Estado sobre esta realidad va a incidir, por tanto, en unas personas y otras, en una gran parte de la sociedad, a fin de cuentas ${ }^{1}$.

¿Es la dependencia un problema individual, un problema de la persona que la padece y, en todo caso, de su círculo familiar (si es que lo tiene)? O, por el contrario, ¿es un problema social, del que debe ocuparse el Estado?

Fundamento constitucional para considerar que estamos ante un problema social que debe ser atendido por el Estado desde luego que lo hay. Puesto que la dignidad humana y el libre desarrollo de la personalidad son la razón de ser del Estado social y democrático, como proclama el artículo $10.1 \mathrm{CE}$. Y, además, teniendo en cuenta que el Estado debe garantizar, en conexión con dicho mandato, una vida digna atendiendo a las necesidades de salud de las personas (artículos 15 y $43 \mathrm{CE}$ ) y promover las condiciones necesarias para asegurar la efectividad de la igualdad y libertad de los individuos, así como su participación en la vida social, de acuerdo con lo que establece el artículo 9.2 CE. Partiendo, además, del hecho de que la mayoría de las personas en situación de dependencia lo son como consecuencia de la disminución de la autonomía por envejecimiento o debido a las secuelas incapacitantes de una enfermedad, encontramos, también, base constitucional en los preceptos que ordenan a los poderes públicos amparar y prestar la atención necesaria a la tercera edad (artículo 50 CE) así como a las personas con discapacidad física, psíquica o sensorial (artículo 49). Y precisamente en estos dos principios rectores se apoya el Tribunal Constitucional al legitimar la acción del Estado sobre la dependencia ${ }^{2}$. Sin embargo, ni todas las personas ancianas son dependientes ni todas las personas que sufren alguna discapacidad precisan en todo caso del auxilio de un tercero para desenvolverse con autonomía ${ }^{3}$. Por ello, lo que realmente está en juego al

\footnotetext{
${ }^{1}$ De acuerdo con el XIX Dictamen del Observatorio Estatal para la Dependencia, de 1 de marzo de 2019, el $3 \%$ de la población española, 1.400 .000 de personas presenta dependencia en alguno de los grados considerados por la Ley.

${ }^{2}$ El TC se ha referido al Sistema de Autonomía y Atención a la Dependencia como "un sistema público y universal de prestaciones económicas y de servicios para hacer efectivo el derecho subjetivo de todo ciudadano, basado en los artículos 49 y 50 CE” (STC 27/2017, de 16 de febrero, FJ.3.a). En el mismo sentido se pronuncia en las SSTC 33/2014, de 27 de febrero, FJ 4 y 18/2016, de 4 de febrero, FJ 7.b).

${ }^{3}$ Así lo señala JiMENA, diferenciando los términos dependencia y discapacidad, y resaltando cómo las condiciones de accesibilidad y el diferente entorno pueden influir de manera determinante y hacer que personas con alguna discapacidad no sean personas dependientes. Vid. Jimena Quesada, L. (2012): “El derecho a la autonomía de las personas con discapacidad", en Escobar Roca (dir.), Derechos sociales y tutela antidiscriminatoria, Pamplona, Aranzadi, págs. 1394 y ss.
} 
abordar la dependencia es el desarrollo de una vida digna y la igualdad efectiva en el disfrute de los derechos y libertades de todas las personas.

La identificación de colectivos especialmente vulnerables que deben ser objeto de protección por los poderes públicos, en aras de garantizar la efectiva igualdad de oportunidades de todos los individuos y grupos en los que se encuentran, es el presupuesto del Estado social de Derecho. La agrupación voluntaria de personas para representar y revindicar mejor sus intereses comunes ha contribuido, sin duda, a visibilizar sus necesidades, a hacer llegar sus demandas a los poderes públicos y a servir de válidos interlocutores entre la ciudadanía y las instituciones a la hora de llevar a cabo políticas públicas. Sin embargo, una cosa es la legítima representación de intereses sobre la base del movimiento asociativo y otra la compartimentación de la sociedad en grupos por parte del poder público. El riesgo de compartimentar en exceso la sociedad, por más que detrás se encuentre el loable propósito de hacer realidad la igualdad, puede hacernos perder la perspectiva de la persona como sujeto de derechos y no como objeto destinatario de la actuación pública. Sobre todo, si esa identificación se lleva a cabo desde la diferencia o excepcionalidad con respecto a un estándar concreto de ciudadanía. Hablar de mujeres, de ancianos, de desempleados, de personas con discapacidad, como si el estándar fuera el de “ciudadano varón”, “adulto”, “activo profesionalmente”, “con plenas capacidades físicas y psíquicas”, además de partir de una premisa artificial y parcial, puede, no sólo estigmatizarlas, sino convertir a las personas que situamos en tales grupos en meros objetos pasivos destinatarios de las políticas públicas ${ }^{4}$.

Todas las personas, desde nuestro nacimiento, hemos precisado del cuidado y atención de otras, hemos vivido, por tanto, una cierta situación de dependencia. Y, a lo largo de la vida, estamos expuestos a vicisitudes de especial vulnerabilidad en las que necesitaremos del auxilio o cuidado de otros: somos susceptibles de caer enfermos, sufrir accidentes y estamos llamados a envejecer. Finalmente, en nuestro proceso vital casi todos nos veremos afectados por la dependencia, ya sea como personas necesitadas de cuidados o como personas cuidadoras. En este sentido, se ha empleado, con acierto, la expresión de "cuidadanía"5 para poner de manifiesto la cualidad de las personas como seres interdependientes, que vivimos precisamente por ello en sociedad, y situar al principio de solidaridad en el motor que debe regir dichas relaciones de interdependencia. Desde el enfoque de las capacidades, que pone el énfasis en las formas complejas de

\footnotetext{
${ }^{4}$ En este sentido se pronuncia JIMENA, quien además subraya la importancia del lenguaje y la conveniencia de no sustantivar situaciones adjetivas de la persona, puesto que ello nos termina conduciendo a identificar a la persona con su adjetivo. En el caso de la discapacidad, "se olvida el sustantivo (persona) y se contempla sólo su condición de discapacitado. Por ello no hablaremos de "discapacitados", sino de "personas". Y, además, no hablaremos de "personas discapacitadas" sino de "personas con discapacidad" pues la discapacidad -como condición- se tiene, pero no se es”, Jimena Quesada, L. (2012): "El derecho a la autonomía de las personas con discapacidad”, op. cit., pág. 1409.

${ }^{5}$ Rodríguez Ruiz, B. (2010), "Hacia un Estado postpatriarcal: Feminismo y cuidadanía", Revista de Estudios Políticos, 149, págs. 87-122.
} 
interdependencia entre las personas y sus medios materiales, sociales y políticos, se busca reconocer la condición humana y no ocultarse de ella ${ }^{6}$.

La necesidad de cuidados, lejos de ser una cuestión accesoria, marginal, puntual, es un asunto absolutamente presente en nuestras vidas. Que no se haya incluido, hasta ahora, entre los principales temas de la agenda política se ha debido, entre otras cosas, a que ha sido considerado un tema en buena parte resuelto en el ámbito doméstico o familiar. Es cierto que la legislación se ocupaba de algunas situaciones de dependencia, especialmente en la medida que incidían en el ámbito laboral (incapacidad permanente, gran invalidez), no desde la perspectiva de la autonomía para la realización de actividades básicas de la vida diaria. Fuera, por tanto, de tales situaciones, la dependencia quedaba al margen de la actuación política. Como un asunto, por tanto, individual, que afectaba a determinadas personas y que hallaba solución en su círculo familiar más próximo. O si no la encontraba, el Estado, al menos, no intervenía, en principio sobre esta realidad.

La dependencia pasa ser considerada asunto de interés social sobre el que el Estado debe intervenir cuando se convierte en un problema mayor motivado por varias causas: De un lado, el considerable aumento de la población en situación de dependencia y que previsiblemente no va a dejar de crecer, como consecuencia de la mayor esperanza de vida alcanzada y del avance de la medicina con tratamientos que logran una mayor supervivencia frente a las enfermedades, aunque no consigan evitar sus secuelas discapacitantes. De otro lado, la incorporación de las mujeres al mercado de trabajo habiendo sido ellas las que hasta entonces asumían en exclusiva en cuidado de las personas dependientes de la familia- junto con los cambios experimentados en los actuales modos de vida (reducción del tamaño de las familias, dispersión geográfica de sus miembros, falta de tiempo, dificultades para conciliar el cuidado de hijos pequeños con el de personas dependientes mayores, etc.). Esta realidad parece presagiar que la solución doméstica a la necesidad de cuidado de las personas dependientes no va a seguir estando disponible por mucho tiempo o no, al menos, en las mismas condiciones. Lo cierto es que las mujeres se han incorporado al espacio público sin que los hombres hayan hecho una inmersión proporcional en el ámbito privado, por lo que la tarea de los cuidados continúa siendo desempeñada por mujeres, actuando como "el Estado de bienestar del resto de la población" ${ }^{7}$, que llevan a cabo dobles y triples jornadas de trabajo conciliando difícilmente vida familiar y profesional. Esta situación, discriminatoria sin duda, se hace cada vez más insostenible, con la consiguiente incertidumbre acerca de quién asumirá el

\footnotetext{
${ }^{6}$ Interesante el análisis del enfoque de las capacidades de MONEREO, que lo considera "particularmente adecuado para proveer el núcleo central a una sociedad que busca reconocer la condición humana (que incluye la animalidad, mortalidad y finitud) en vez de ocultarse de ella, llamando en su ayuda a la vergüenza y a la repugnancia”. Vid. Monereo Pérez, J. L., (2007) “El Modelo de protección de la dependencia: el derecho subjetivo de ciudadanía social”, Documentación Administrativa, 276-277, págs. 596 y ss.

${ }^{7}$ Martínez Sampere, E. (2014) "Ciudadanía democrática, voluntad política y estado social”, Igualdad y Democracia: el género como categoría de análisis jurídico, Valencia, Corts Valencianes, pág. 446.
} 
cuidado de las siguientes generaciones de personas dependientes. Como señala MARRADES, “las mujeres no están dispuestas a seguir prestando esa función en exclusiva: ni ser cuidadoras exclusivamente ni ser exclusivamente ellas las que cuidan” ${ }^{8}$. Parte de la solución comienza por que hombres y mujeres asuman de forma equitativa la responsabilidad del cuidado de las personas dependientes y de todo lo doméstico. Por más que resulte de una lógica tan aplastante y fácil formulación, la realidad es tozuda y la distribución de roles entre mujeres y hombres se resiste a un cambio tan sustancial. "El reparto equitativo del trabajo doméstico es el elemento fundamental que se intenta obviar una y otra vez, pero que sigue apareciendo tenazmente como la clave de la cuestión”9. Pero, incluso logrando la corresponsabilidad y consiguiente reparto equitativo de lo doméstico, no sería suficiente para garantizar una calidad en el cuidado y atención de las personas dependientes compatible con el desarrollo personal de las personas cuidadoras, siendo necesarias políticas públicas de atención a la dependencia. Tampoco se cubriría la situación de aquellas personas dependientes sin familia o una red social de apoyo, problema a tomar en consideración a la vista del crecimiento del número de personas que viven solas.

Las reivindicaciones de movimientos feministas, de plataformas representantes de personas dependientes y el impulso de instrumentos de carácter internacional como la Recomendación n. ${ }^{\circ}$ (98) 1998, del Comité de Ministros del Consejo de Europa relativa a la dependencia ${ }^{10}$, contribuirían finalmente a la aprobación de la Ley de Promoción de la Autonomía Personal y Atención a las Personas en Situación de Dependencia.

\section{EL CUIDADO COMO DERECHO SOCIAL FUNDAMENTAL}

La débil exigibilidad de los derechos sociales ante los tribunales de justicia se ha venido basando en el argumento de que estos derechos no comparten la misma estructura que los derechos fundamentales, entendidos como los clásicos derechos civiles y políticos. Así, mientras que los derechos fundamentales imponen al Estado básicamente obligaciones negativas, los derechos sociales exigen para su disfrute efectivo la actuación de los poderes públicos a través de medidas que, en la mayoría de los casos, comportan la disposición de recursos económicos. En tal sentido, resulta más factible frenar la injerencia o actividad obstaculizadora del poder público que impida o dificulte gravemente el ejercicio de un derecho de libertad que imponer al Estado la realización de una prestación que comporte un gasto económico. En consecuencia, los derechos sociales no serían directa e inmediatamente amparables por los órganos jurisdiccionales a partir

\footnotetext{
${ }^{8}$ Marrades Puig, A. (2016), "Los nuevos derechos sociales: el derecho al cuidado como fundamento del pacto constitucional”, Revista de Derecho Político, 97, pág. 236.

${ }_{9}^{9}$ Martín Cano, M. C. y Ruiz Seisdedos, S. (2010), “La Ley de Dependencia: una mirada con perspectiva de género”, Documentos de Trabajo Social, 48, pág. 95.

${ }^{10}$ Adoptada por el Comité de Ministros el 18 de septiembre de 1998.
} 
del enunciado constitucional. Corresponde al poder legislativo concretar la forma que adoptará la prestación, de entre todas las posibles, y tomar, en función de los recursos financieros disponibles, las decisiones presupuestarias correspondientes ${ }^{11}$. Precisamente en estos términos queda recogida la garantía de los derechos sociales en la Constitución Española, cuyo artículo 53.3 establece que "sólo podrán ser alegados ante la jurisdicción ordinaria de acuerdo con lo que dispongan las leyes que los desarrollen”.

De este modo, frente a los derechos subjetivos fundamentales, realizables directamente y protegibles de inmediato por los órganos jurisdiccionales, los derechos sociales se conciben como mandatos jurídico-objetivos dirigidos básicamente al legislador y a la Administración, con capacidad para determinar cómo satisfacer su ejercicio. Los derechos sociales se presentan, así, como mandatos de optimización que pueden cumplirse en diferente grado ${ }^{12}$.

En relación con el derecho a la atención y autonomía de las personas en situación de dependencia, el Tribunal Constitucional ha fundamentado la actuación del legislador, a la hora de regular el acceso a tales prestaciones, en los artículos 49 CE (discapacidad) y 50 CE (tercera edad). La Ley de Dependencia vendría, por tanto, a dar concreción a tales principios principios rectores de la política social y económica que, de acuerdo con una lectura formalista del artículo 53.3 CE, carecen de la eficacia directa o efectividad inmediata propia de los derechos fundamentales ${ }^{13}$.

Sin embargo, desde la doctrina se alzan voces que vienen discutiendo, desde hace ya tiempo, esta distinción formal entre unos derechos y otros, considerando que todos, en suma, comportan para el Estado un complejo de obligaciones negativas y positivas a fin de garantizar su ejercicio ${ }^{14}$. Se relativiza así la diferente estructura entre unos derechos clásicos de libertad y otros derechos sociales de prestación, desde el momento en que también entre los derechos civiles encontramos algunos que requieren de la necesaria intervención del Estado para su realización (derecho al sufragio, derecho a la tutela judicial, etc.). Lo que sucede es que las funciones positivas necesarias para ejercer tales derechos civiles -como la tutela judicial efectiva o la participación política- se han considerado, desde el surgimiento mismo del Estado moderno, funciones propias, naturales del Estado, y sólo se ha puesto el énfasis en los límites de su actuación. Es evidente que, aun habiendo derechos que se pueden ejercer, en muchos casos, sin

11 Böckenförde, E. (1993), Escritos sobre derechos fundamentales, Baden Baden, Nomos Verlagsgesellschaft, pág.77.

12 Alexy, R. (2007), Derechos sociales y ponderación, Madrid, Fundación Coloquio Jurídico Europeo, pág. 20.

13 Terol Becerra, M. (2012), "Treinta años de desarrollo constitucional y legislativo de los derechos sociales: derechos ciudadanos y principios rectores”, Derechos sociales y principios rectores. Actas del IX Congreso de la Asociación de Constitucionalistas de España, Valencia, Tirant lo Blanch, pág. 56.

14 Abramovich, V. y Courtis, CH. (2002), Los derechos sociales como derechos exigibles, Madrid; Pisarello, G. (2007), Los derechos sociales y sus garantías, Madrid, Trotta, págs. 111 y ss. 
intervención estatal (como la libertad de expresión o la libertad ideológica), otros, que comparten lugar en el mismo catálogo, sí requieren que el Estado cree las condiciones necesarias para su ejercicio; condiciones que pasan por la regulación legal, la creación de una estructura orgánica y administrativa, la puesta a disposición de recursos económicos, etc. Y nada ha impedido que, en nuestra Constitución, se incluyera entre los derechos fundamentales, un derecho tan eminentemente social, de acuerdo con las características estructurales de la concepción clásica de los derechos sociales, como el derecho a la educación (artículo $27 \mathrm{CE}$ ), revistiéndolo de la eficacia directa y por tanto, inmediatamente exigibilidad antes los tribunales.

Siguiendo con el argumento, los derechos fundamentales generan no sólo obligaciones negativas, sino también obligaciones positivas, obligaciones de hacer. Sin olvidar la dimensión social que han adquirido todos como consecuencia de la evolución del propio Estado, debiendo éste asumir, al margen de su consideración de derechos individuales subjetivos, una función hacia la colectividad (el derecho a la propiedad, el derecho a la información). Por su parte, los llamados derechos sociales, aunque han sido definidos como derechos de prestación -la más importante obligación que imponen al Estado es la de procurar los medios materiales, personales y económicos necesarios para su ejercicio, también implican el deber de no actuar en contra de los mismos. A este respecto, quizás resulte interesante hablar más bien de niveles de obligaciones estatales y no tanto de obligaciones positivas o negativas: obligación de respetar, obligación de proteger, obligación de garantizar y obligación de promover ${ }^{15}$.

En definitiva, desde esta postura doctrinal, se propugna una identidad estructural entre los derechos civiles y políticos y los derechos económicos, sociales y culturales. Unos y otros requieren que el Estado los respete (no interviniendo, por ejemplo, con la censura previa en la libertad de expresión; no destruyendo el patrimonio cultural, etc.), los proteja (asegurando, a través de las fuerzas policiales, que una manifestación pueda celebrarse sin que lo impidan “contramanifestantes” violentos), los garantice (asegurando, por ejemplo, la asistencia sanitaria para todos) y los promueva (con programas de prevención contra la drogodependencia, por ejemplo), aunque, claro está, en distinta medida en función de la naturaleza de cada concreto derecho. Dependiendo de sus peculiaridades habrá derechos que requieran mayor garantía y promoción, mientras que otros precisarán, ante todo, respeto y protección.

Se defiende así la identidad estructural entre los derechos civiles y políticos y los derechos económicos, sociales y culturales, sin olvidar que la propia Carta de Derechos Fundamentales de la Unión Europea, investida de fuerza jurídicamente vinculante por virtud del art. 6.1 del Tratado de la Unión Europea, parte precisamente de la

${ }^{15}$ Van Hoof, G. (1984), "The legal nature of economic, social and cultural rights: A rebuttal of some traditional views”, en Alston, P. y TOMASEVSKI, K., The Right to Food, Utrecht. 
interdependencia e indivisibilidad de todos los derechos fundamentales. Como señala ESCOBAR, "si un derecho cuenta con las dos garantías típicas de la Constitución normativa (vinculación del legislador y tutela judicial directa) es ya un derecho fundamental, con independencia del lugar de la Constitución donde se encuentre" ${ }^{16}$. O como sostiene REVENGA, "una cosa es tener cerrada la vía del amparo para la protección de ciertos derechos, y otra muy distinta extraer de tal exclusión un juicio global de carácter negativo sobre el alcance, la efectividad y hasta el estatuto constitucional de los mismos”17.

Precisamente la interdependencia de los derechos se ha puesto de manifiesto en algunas resoluciones del Tribunal Constitucional que han establecido una clara conexión entre principios rectores y derechos fundamentales, permitiendo de este modo que los derechos sociales alcancen una mayor efectividad. Tal ha sido el caso del derecho a un medioambiente adecuado para el desarrollo de la persona (artículo $45 \mathrm{CE}$ ) cuando se ha conectado con el derecho a la intimidad personal y familiar (artículo $18 \mathrm{CE}$ ) ${ }^{18}$; o el derecho a la protección de la salud (artículo 43 CE) en conexión con el derecho a la vida (artículo $15 \mathrm{CE})^{19}$. Idéntica conexión podría darse en el caso de la situación de dependencia que sufren personas ancianas y personas con discapacidad con el derecho a la vida y a la integridad física y moral (artículo $15 \mathrm{CE}$ ), teniendo presente que debe ser una vida digna (artículo 10.1 CE) y conectándolo también con el derecho a la igualdad y no discriminación por circunstancias personales (artículos 14 y $9.2 \mathrm{CE}$ ). Derechos que debemos interpretar a la luz de la Declaración Universal de Derechos Humanos y de los tratados internacionales, de conformidad con el artículo 10.2 CE. En este sentido, encontramos "el derecho a un nivel de vida adecuado" reconocido en la Declaración Universal de Derechos Humanos ${ }^{20}$ y en el Pacto Internacional de los Derechos Económicos, Sociales y Culturales ${ }^{21}$, que además procura la "mejora continua de las condiciones de existencia”; el derecho de las personas ancianas "a llevar una vida independiente" en el Protocolo Adicional de la Carta Social Europea ${ }^{22}$ de 1988; el derecho de las personas con discapacidad “a vivir de forma independiente y ser incluidas

\footnotetext{
${ }^{16}$ Escobar Roca, G. (2012) “Los derechos fundamentales sociales de prestación”, en Escobar Roca (dir.), Derechos sociales y tutela antidiscriminatoria, Pamplona, Aranzadi, pág. 462.

${ }^{17}$ Revenga Sánchez, M., (2009) "Los derechos sociales (instrumentos de garantía en la Constitución Española)”, Revista Parlamentaria de la Asamblea de Madrid, 21, pág. 103.

18 Vid. STC 119/2001, de 24 de mayo.

${ }^{19}$ Vid. STC 160/2007, de 2 de julio.

${ }^{20} \mathrm{El}$ artículo 25.1 DUDH reconoce a toda persona "el derecho a un nivel de vida adecuado que le asegure, así como a su familia, la salud y el bienestar, y en especial...la asistencia médica y los servicios sociales necesarios".

${ }^{21}$ El artículo 11.1 PIDESC proclama que los Estados partes reconocen "el derecho de toda persona a un a un nivel de vida adecuado para sí y su familia, y a una mejora continua de las condiciones de existencia, y que han de tomar las medidas apropiadas para asegurar la efectividad de ese derecho”.

${ }^{22}$ Dicho Protocolo establece, en la parte II, artículo 4, que las Partes se comprometen a permitir "a las personas ancianas escoger libremente su modo de vida y llevar una vida independiente en su entorno habitual durante todo el tiempo que lo deseen y que sea posible, mediante, entre otras acciones, la asistencia sanitaria y los servicios que su estado requiera, así como a garantizar a las personas ancianas que viven en instituciones, la asistencia apropiada dentro del respeto a su vida privada”.
} 
en la sociedad" en la Convención sobre los Derechos de las Personas con Discapacidad ${ }^{23}$, de 2006; y el derecho a la protección en el caso de la dependencia en la Carta de los Derechos Fundamentales de la Unión Europea de 2007 y más expresamente el derecho de las personas a "recibir los cuidados que exija su estado" en la Carta Social Europea ${ }^{24}$ Tratado, que, como señala SALCEDO, es el más importante en cuanto a la protección de los derechos humanos sociales dado que "al equipararlos al resto de derechos, establece un nivel de protección más elevado que el de las normas estatales”25.

La idea de un continuum de derechos plantea, por otro lado, el problema de si el Estado se encuentra en condiciones de soportar la exigibilidad inmediata de todos ellos en la medida en que los recursos económicos no son ilimitados. Y mucho más en tiempos de crisis o recesión económica. Aunque, cuando se afirma que el condicionante económico de los derechos sociales impide su eficacia directa, se olvida, como advierte JIMENA al abordar el derecho a la atención de las personas en situación de dependencia, que su justiciabilidad y coste financiero son semejantes a los clásicos derechos fundamentales de libertad ${ }^{26}$. Pero, además, quizás se esté identificando, de forma simplista, la obligación positiva que generan los derechos sociales con la idea de prestación y coste económico para el Estado. Y es que el Estado puede asegurar el derecho a través de otros medios, implicando a otros sujetos obligados: bien a través de normas facultativas o que concedan relevancia a una situación determinada (protección jurídica a la familia) atribuyéndole consecuencias jurídicas; bien a través de normas que restrinjan o limiten las facultades de otras personas o les impongan, incluso, obligaciones (excedencia por cuidado de familiares). Y, en fin, el Estado puede cumplir con su obligación prestando los servicios no sólo en régimen exclusivo, sino también a través de formas mixtas de cobertura (en colaboración con el Tercer Sector).

Quizás la clave está en fijar niveles esenciales de cumplimiento, dejando a los distintos sistemas que caracterizan al constitucionalismo multinivel la determinación de las políticas propias para alcanzar dichos estándares ${ }^{27}$. Reconociendo, en todo caso, que la limitación de recursos económicos es un factor que condiciona el cumplimiento de tales

\footnotetext{
${ }^{23}$ El artículo 19 CDPD reconoce el derecho de éstas "a vivir de forma independiente y a ser incluido en la comunidad" y, en consecuencia, obliga a los Estados parte a tomar medidas para que "las personas con discapacidad tengan acceso a una variedad de servicios de asistencia domiciliaria, residencial y otros de apoyo de la comunidad, incluida la asistencia personal que sea necesaria para facilitar su inclusión en la comunidad y para evitar su aislamiento o separación de ésta”.

${ }^{24}$ El artículo 13 CSE recoge el derecho de las personas sin recursos suficientes "el derecho a una asistencia social y médica adecuada y, en caso de enfermedad, a recibir los cuidados que exija su estado, para prevenir, eliminar o aliviar su estado de necesidad personal o familiar”.

25 Salcedo Beltrán, C. (2016), "La aplicabilidad directa de la Carta Social Europea por los órganos judiciales”, Trabajo y derecho: nueva revista de actualidad y relaciones laborales, 13, pág. 50. Beltrán considera necesario una mayor invocación de la CSE como un instrumento de garantía en las reivindicaciones ante los tribunales para que se superen las dudas o recelos de los mismos en su aplicación. ${ }^{26}$ Jimena Quesada, L. (2012): “El derecho a la autonomía de las personas con discapacidad”, op. cit., pág. 1408.

${ }^{27}$ Cascajo Castro, J.L. (2009), “Los derechos sociales, hoy”, Revista catalana de dret públic, 38, pág. 34.
} 
obligaciones, los poderes públicos habrán de acreditar que han realizado todo el esfuerzo a su alcance para utilizar la totalidad de los recursos disponibles a fin de satisfacer esas obligaciones mínimas y, aplicando la "teoría de los derechos fundamentales sociales mínimos”, llegado el caso, como plantean ALONSO y ALEMÁN "restringir el derecho, en el supuesto de no poder hacerlo más extensivo, a aquellas personas que, por sus circunstancias personales y sociales, se encuentren en situación de mayor necesidad de tercera persona y no puedan remediarla con sus propios recursos”28.

Siendo deseable una nueva redacción y reordenación de los derechos reconocidos en nuestro texto constitucional -para adaptarse a la nueva realidad de nuestro tiempo, evitar expresiones que pueden resultar denigrantes ("minusválidos") o terminar con la sorprendente diferente posición que ocupan el derecho a la fundación (art. 34 CE) y el derecho a la salud (art. $43 \mathrm{CE}$ ), por ejemplo-, no parece que la reforma de la Constitución vaya a poder producirse en un futuro próximo. En un contexto ideal sería preferible la reubicación de los derechos sociales en la categoría de derechos fundamentales mediante la reforma de la Constitución, incorporando además entre ellos el derecho al cuidado como un "nuevo derecho social fundamental ${ }^{29}$. Social por cuanto se refiere a la prestación de atender y facilitar el bienestar de las personas, y fundamental porque es esencial para una vida digna. En el momento actual y en tanto dicha reforma constitucional no se lleve a cabo, el reto habrá de situarse en la defensa de la eficacia y fundamentalidad del derecho social al cuidado a través de otros cauces.

En este sentido, gracias a la aprobación de la Ley de Promoción de la Autonomía Personal y Atención a las Personas en Situación de Dependencia estamos ante un nuevo derecho social que, configurado como "derecho subjetivo de ciudadanía”, aunque no se encuentre constitucionalizado sí es exigible precisamente por ese desarrollo normativo y puede encontrar un grado adicional de garantía en conexión con los derechos fundamentales a la vida e integridad física y moral y a la igualdad y no discriminación ${ }^{30}$. De este modo, la línea de separación entre derechos fundamentales y principios rectores se va haciendo cada vez más tenue, como señala CASCAJO, quien apuesta por no refugiarnos en una "lectura simplista del artículo 53.3 CE” ${ }^{31} \mathrm{y}$, en su lugar, considerar el modo a través del

\footnotetext{
${ }^{28}$ Alonso Seco, J. M. y Alemán Bracho, C. (2017), "Las prestaciones de atención a la dependencia y su consideración como derechos sociales”, Revista de Derecho Político, 100, pág. 1018.

${ }^{29}$ MARRADES aboga por introducir "un derecho al cuidado, que va más allá del derecho a la salud, y que es una proyección del derecho a la vida, del derecho a una vida digna y que podría incluir no sólo el derecho a ser cuidado/a sino también el derecho a cuidar, sin que ello menoscabe otras facetas de la personalidad humana”. Vid. Marrades Puig, A. (2016), "Los nuevos derechos sociales: el derecho al cuidado como fundamento del pacto constitucional”, op. cit., pág. 223.

${ }^{30}$ Vid. Tenorio Sánchez, P. (2014), "El Tribunal Constitucional, la cláusula del estado social y los derechos sociales”, en Terol Becerra, M., Jimena Quesada, L. (dir.) Tratado sobre Protección de Derechos Sociales, Valencia, Tirant lo Blanch, págs. 135-141.

${ }^{31}$ Interesante la alternativa interpretación del artículo 53.3 CE que ofrece EsCOBAR para sustentar la eficacia directa de los derechos sociales recogidos en el capítulo III de la Constitución. Vid. Escobar Roca, G. (2012)
} 
cual los desarrollos normativos han ido moldeando el régimen jurídico de estos derechos ${ }^{32}$.

Incluso desde las posiciones que sólo ven en los derechos sociales mandatos de optimización se afirma la obligación de progresividad -recogida en textos internacionales (artículo 2.1 PIDESC)- que implica que la satisfacción plena de los derechos sociales se logra forma gradual, a través de medidas que supongan mejorar las condiciones de su ejercicio. Los poderes públicos han de dar pasos para avanzar progresivamente en su consecución, pero les está prohibido retroceder o empeorar la situación de estos derechos. Se habla así de una obligación de no regresividad que impide reducir los niveles de protección de los derechos sociales o derogarlos ${ }^{33}$.

Pues bien, esta obligación de no regresividad puede ser precisamente uno de los elementos justiciables de los derechos sociales que permitan denunciar aquellas actuaciones de los poderes públicos que comporten una manifiesta reducción de los niveles de protección alcanzados en relación con algunos derechos sociales. Y la Ley de Dependencia, con el establecimiento de este nuevo derecho subjetivo de ciudadanía constituye, sin duda, un paso decisivo, sin posibilidad de retorno, para que las políticas de atención a las personas dependientes se conviertan en derechos sociales, en derechos humanos sociales fundados en la igualdad y en la justicia ${ }^{34}$.

En época de crisis económica y, consiguientemente, de mayores dificultades para los sectores más vulnerables de la sociedad, la garantía de los derechos sociales no puede debilitarse sino ser una de las prioridades del Estado social de Derecho. Y mucho más si se tiene en cuenta que encuentran su fundamento en la libertad fáctica y en la dignidad humana y su evidente conexión con el principio democrático. Como se ha dicho, los derechos sociales son el sustento vital para el ejercicio de los demás derechos ${ }^{35}$.

\section{LA CONSAGRACIÓN DE UN DERECHO SUBJETIVO A LA AUTONOMÍA EN LA LEY DE DEPENDENCIA. BALANCE DE DOCE AÑOS DE VIGENCIA}

La Ley 39/2006, de 14 de diciembre, de Promoción de la Autonomía Personal y Atención a las Personas en Situación de Dependencia o Ley de Dependencia (en adelante LAAD),

\footnotetext{
“Presupuestos de teoría dogmática y constitucional”, en Escobar Roca (dir.), Derechos sociales y tutela antidiscriminatoria, Pamplona, Aranzadi, págs. 296 y ss.

32 Cascajo Castro, J. L. (2012), “Derechos sociales” en Cascajo Castro, J. L., et al. (coord.), Derechos sociales y principios rectores. Actas del IX Congreso de la Asociación de Constitucionalistas de España, Valencia, Tirant lo Blanch, págs. 25-26.

${ }^{33}$ Böckenförde, E. (1993), Escritos sobre derechos fundamentales, op. cit., pág.78.

${ }^{34}$ Alonso Seco, J. M. y Alemán Bracho, C. (2017), "Las prestaciones de atención a la dependencia y su consideración como derechos sociales”, op. cit., pág. 1019.

${ }^{35}$ Ferrajoli, L., Moreso, J.J. y Atienza, M. (2008), La Teoría del derecho en el paradigma constitucional, Madrid, Fundación Coloquio Jurídico Europeo, pág. 81
} 
nace con el propósito de abordar la cuestión de la dependencia humana de manera integral, haciendo de ella y de los cuidados que exige objeto de actuación del poder público. Y lo hace a partir del reconocimiento del "derecho subjetivo de ciudadanía a la promoción de la autonomía personal y atención a las personas en situación de dependencia”36. A tal fin, define la dependencia como el “estado de carácter permanente en que se encuentran las personas que, por razones derivadas de la edad, la enfermedad o la discapacidad, y ligadas a la falta o a la pérdida de autonomía física, mental, intelectual o sensorial, precisan de la atención de otra u otras personas o ayudas importantes para realizar actividades básicas de la vida diaria o, en el caso de las personas con discapacidad intelectual o enfermedad mental, de otros apoyos para su autonomía personal”37.

El objeto de la ley es regular las condiciones que garanticen la igualdad efectiva en el ejercicio de tal derecho "mediante la creación de un sistema para la autonomía y atención a la dependencia con la colaboración y participación de todas las Administraciones Públicas y la garantía por la Administración General del Estado de un contenido mínimo común de derechos para todos los ciudadanos en cualquier parte del territorio del Estado español”38.

Sin ánimo de llevar a cabo un análisis exhaustivo de la Ley, que ya ha sido objeto de numerosos estudios ${ }^{39}$, se hacen, a continuación algunas consideraciones en relación con algunas de las cuestiones que han suscitado un mayor interés desde el punto de vista de la efectividad del derecho y de su impacto de género.

La principal novedad de la ley es el establecimiento por primera vez, en el ámbito de los servicios sociales, de un “derecho subjetivo de ciudadanía”, dando la categoría de derechos a determinados servicios sociales relacionados con la dependencia. Esto supone, como señala JiMENA, elevar a la persona en situación de dependencia a la posición de verdadero titular y sujeto activo de un derecho directamente ejercitable, y no de mero sujeto pasivo u objeto receptor de una acción pública social paternalista. Se trata con ello de reafirmar su posición de "sujetos activos que comparten con el conjunto de personas

\footnotetext{
${ }^{36}$ Artículo 1 LAAD.

${ }^{37}$ Artículo 2.2 LAAD.

${ }^{38}$ Artículo 1.1 LAAD.

39 Montoya Melgar, A. dir. (2007), La protección de las personas dependientes: comentario a la Ley 39/2006, de promoción de la autonomía personal y atención a las personas en situación de dependencia, Cizur Menor, Thomson-Civitas; Monereo Pérez, J. L., coord. (2007), La protección jurídica de las situaciones de dependencia: estudio sistemático de la Ley 39/2006, de 14 de diciembre, de promoción de la autonomía personal y atención a las personas en situación de dependencia, Granada, Comares; Sempere Navarro, A. V. dir. (2008), Comentario sistemático de la Ley de la dependencia: Ley 39/2006, de 14 de diciembre, de promoción de la autonomía personal y atención a las personas en situación de dependencia y normas autonómicas, Cizur Menor, Thomson- Aranzadi; González Ortega, S. (2010), Informe sobre la Ley de promoción de la autonomía personal y atención a las personas en situación de dependencia, Madrid, Fundación Democracia y Gobierno Local; Cavas Martínez, F. (2007), Ley de dependencia: estudio de la Ley 39/2006, de 14 diciembre, sobre promoción de la autonomía personal y atención a las personas en situación de dependencia, Cizur Menor, Thomson-Aranzadi, entre otros.
} 
el estatuto jurídico de plena ciudadanía para un ejercicio efectivo del derecho a la autonomía, la integración social y la participación en la vida de la comunidad”40.

La Ley de Dependencia trata, al mismo tiempo, de universalizar tal derecho de la ciudadanía, garantizando un nivel mínimo común de protección de todas las personas con independencia del lugar en el que residan, habilitado por el título competencial del artículo 149.1.1 CE que le permite establecer las condiciones básicas ${ }^{41}$ que garanticen la igualdad de todos los españoles en el ejercicio de sus derechos ${ }^{42}$. Estamos, por tanto, ante una ley que opera en la práctica como una "ley marco", tratando de forma directa, coordinada y específica la dependencia, que hasta entonces había sido objeto de atención parcial e inespecífica por la Seguridad Social y los servicios sociales de las Comunidades Autónomas. A tal fin crea el Sistema Nacional de Atención a la Dependencia que habrá de responder a una acción coordinada y cooperativa entre todas las Administraciones implicadas: Estado, CC.AA. y Corporaciones Locales. Este nivel mínimo de protección, garantizado a cada uno de los beneficiarios del sistema, constituiría las condiciones básicas del ejercicio del derecho a la autonomía de las personas en situación de dependencia. Condiciones que podrían verse mejoradas por las Comunidades Autónomas en dos niveles más: uno mediante acuerdo entre cada Comunidad Autónoma y el Estado (a través del correspondiente convenio) y otro adicional que puede establecer unilateralmente cada Comunidad Autónoma, a través de su correspondiente legislación y desarrollo reglamentario ${ }^{43}$, en base a su competencia exclusiva en asistencia social ${ }^{44}$.

La Ley asume el tema de la dependencia como un asunto social sobre el que los poderes públicos deben actuar, y lo hace reconociendo en la misma Exposición de Motivos que, hasta entonces, el cuidado de las personas dependientes había sido asumido por las familias, pero sobre todo por las mujeres. Teniendo en cuenta factores como los cambios en el modelo de familia y la incorporación progresiva de las mujeres al mercado de trabajo, el legislador pone de manifiesto que este sistema tradicional de atención debe ser

\footnotetext{
40 Jimena Quesada, L. (2012): “El derecho a la autonomía de las personas con discapacidad”, op. cit., pág. 1409.

${ }^{41}$ El TC sostiene la idoneidad del artículo 149.1.1 CE, como título competencial que sirve de fundamento para el reconocimiento de derechos subjetivos de atención a la situación de dependencia, estableciendo, asimismo, la relación de este último título competencial con los principios rectores directamente relacionados con el sistema de atención a la dependencia, como son los artículos 49 y 50 CE (STC 18/2016, de 4 de febrero, FJ 7). MONEREO advierte, sin embargo, de las tensiones competenciales y problemas de coordinación a que dará lugar este título competencial (en lugar del artículo 149.1.17 CE) por su "debilidad" frente al del 148.1.20 CE, que confiere la competencia exclusiva de las CCAA en materia de asistencia social y servicios sociales (Monereo Pérez, J. L. (2007), "El Modelo de protección de la dependencia: el derecho subjetivo de ciudadanía social”, op. cit., pág. 625).

42 De acuerdo con el artículo 5 LAAD, titulares de este derecho son los españoles que, teniendo acreditado el estado de dependencia (tras la correspondiente valoración), residan en España y lo hayan hecho durante cinco años, dos de los cuales sean inmediatamente anteriores a la fecha de presentación de la solicitud.

${ }^{43}$ Monereo Pérez, J. L., (2007), "El Modelo de protección de la dependencia: el derecho subjetivo de ciudadanía social”, op. cit., pág. 624.

${ }^{44}$ Artículos 7, 9, 10 y 32 LAAD.
} 
revisado si se quiere garantizar "una adecuada capacidad de prestación de cuidados a aquellas personas que los necesitan”. La perspectiva de género se recoge en la fundamentación de la ley y, a su vez, se incorpora como uno de sus principios inspiradores en el articulado ${ }^{45}$.

El contenido de este nuevo derecho subjetivo va a traducirse en dos tipos de prestaciones: prestaciones en especie, consistentes en el disfrute de un servicio, y prestaciones económicas, consistentes en una cantidad de dinero que se entrega directamente al beneficiario. Las prestaciones en especie contempladas en la ley son los denominados “servicios de promoción de la autonomía personal y de atención y cuidado”, entre los que se encuentran los programas de prevención y promoción de la autonomía, la teleasistencia, la ayuda a domicilio (para la realización de las actividades básicas de la vida diaria o para las necesidades domésticas o del hogar), los centros de día y de noche (que ofrecen una atención integral durante el periodo diurno o nocturno) y la atención residencial en centros públicos o concertados (que puede tener carácter permanente, cuando el centro residencial se convierta en la residencia habitual de la persona, o temporal $)^{46}$. Dichas prestaciones persiguen promover la autonomía de la persona en situación de dependencia (por ejemplo, la teleasistencia o ayuda a domicilio) pero, al mismo tiempo, se enfocan también como apoyo a las familias que asumen el cuidado principal de tales personas, facilitando su descanso o respiro y tomando en consideración la posible enfermedad u hospitalización de la persona cuidadora: tal es el caso de los centros de día o de noche o de la estancia temporal en residencias.

Las prestaciones económicas recogidas en la LAAD las recibe la persona en situación de dependencia y están condicionadas al fin para el que son concedidas. Se distinguen tres tipos: prestaciones vinculadas a un servicio, prestaciones para cuidados en el entorno familiar y de apoyo a cuidadores no profesionales y, por último, prestaciones económicas de asistencia personal ${ }^{47}$. La prestación económica vinculada a un servicio se concederá de manera periódica en aquellos casos en los que no sea posible el acceso a un servicio público o concertado de atención y la persona beneficiaria tenga que acudir a un servicio privado para el que se destina tal ayuda. La prestación económica para cuidados en el entorno familiar está prevista para cuando el beneficiario esté siendo atendido en su entorno familiar, debiendo la persona cuidadora a la que se destinará tal cantidad económica, ajustarse a las normas sobre cotización a la Seguridad Social determinadas reglamentariamente. Finalmente, la prestación de asistencia personal tiene como finalidad permitir la contratación de una asistencia personal, durante un número de horas, para facilitar al beneficiario una vida más autónoma, tanto en el ejercicio de las actividades básicas de la vida diaria, como en el acceso a la educación y al trabajo.

\footnotetext{
${ }^{45} \mathrm{El}$ artículo 3 p) LAAD enuncia entre tales principios "la inclusión de la perspectiva de género, teniendo en cuenta las distintas necesidades de mujeres y hombres".

${ }^{46}$ Artículos 15.1 y 21 a 25 LAAD.

${ }^{47}$ Artículos 17 a 19 LAAD.
} 
Todas estas prestaciones son incompatibles entre sí: o bien se opta por una de las tres prestaciones económicas, o bien se opta por una de las distintas prestaciones de servicios. Únicamente el servicio de teleasistencia es compatible con cualquier prestación económica o con cualquier otro servicio (salvo el de atención residencial, por razones obvias $)^{48}$.

El reconocimiento del derecho a un tipo de prestación u otra se determina conforme a un complejo proceso que se inicia a instancia de la propia persona interesada (o de su representante) y que comienza con la valoración de la situación de dependencia por los órganos autonómicos encargados de ello. Esta valoración se realiza de acuerdo con el baremo que se acuerde en el Consejo Territorial de Servicios Sociales y determinará el grado de dependencia: dependencia moderada (grado I), dependencia severa (grado II) y gran dependencia (grado III). A través de un procedimiento participativo en el que se consulta a la persona beneficiaria y, en su caso, a su familia, los servicios sociales autonómicos establecen un Programa Individual de Atención, que contempla las modalidades de intervención más adecuadas a sus necesidades de entre los servicios y prestaciones económicas previstos en la resolución para su grado ${ }^{49}$.

El sistema de atención a la dependencia configurado en la Ley opta abiertamente por las prestaciones asistenciales frente a las monetarias, estableciendo una clara preferencia por la prestación de servicios y considerando excepcionales las prestaciones económicas, que actuarán de manera subsidiaria, sólo cuando no sea posible la atención mediante los servicios ofertados públicamente por el sistema. Desde una perspectiva de género, un modelo preferentemente asistencial tendría un impacto positivo al sustituir al cuidado familiar o informal, que recae mayoritariamente sobre las mujeres y que dificulta -cuando no impide- la inserción, promoción y reincorporación de las mujeres cuidadoras al mercado de trabajo ${ }^{50}$. Diversos factores, sin embargo, han hecho que la excepcionalidad se convierta en la regla y la tendencia, por tanto, ha sido precisamente la contraria, como habían apuntado algunos autores ${ }^{51}$. En efecto, la elección del beneficiario, que mayoritariamente prefiere permanecer en su domicilio y ser atendido por personas de su entorno familiar -pauta generalizada en nuestro contexto socio-cultural-, unida al mayor coste económico de los servicios públicos o concertados, así como a la complejidad de su puesta en funcionamiento, ha dado lugar a la generalización de las prestaciones para cuidados en el entorno familiar y de apoyo a cuidadores no profesionales.

\footnotetext{
48 Artículo 25 bis LAAD.

49 Artículos 26, 27, 28 y 29 LAAD.

50 Monereo Pérez, J. L., (2007), “El Modelo de protección de la dependencia: el derecho subjetivo de ciudadanía social”, op. cit., pág. 619.

51 Ibid., pág. 622. En el mismo sentido, Rodríguez Cabrero, G. (2007), "La protección social de la dependencia en España. Un modelo sui generis de desarrollo de los derechos sociales”, Política y Sociedad, 44, 2, pág. 74.
} 
De este modo, se ha producido el "efecto perverso" 52 de consolidar la situación de discriminación de las mujeres, que en lugar de salir del ámbito doméstico del cuidado o de la difícil compatibilización de su vida profesional con el cuidado de una persona dependiente (el cuidado es una de las principales razones alegadas por las mujeres a la hora de optar por un empleo a tiempo parcial, lo que incide claramente en la brecha salarial y de pensiones $)^{53}$, perpetúan ese rol con la solución legal de ser “compensadas” económicamente ${ }^{54}$. Se ha pasado así de una situación de informalidad a una especie de "subempleo" 55 , por cuanto se trata de sujetos excluidos del ámbito laboral y de la generalidad de las garantías que las normas laborales establecen para la realización de la prestación de servicios.

Ante la tozuda realidad de un cuidado informal feminizado ${ }^{56}$ que, lejos de evolucionar hacia un reparto equitativo entre hombres y mujeres, corre el riesgo de perpetuarse con medidas aparentemente protectoras o de auxilio, hay quienes abogan por políticas públicas de apoyo a una tarea tan intensa como prolongada en el tiempo: ya sea flexibilizando el acceso a las prestaciones monetarias, ampliando las medidas de conciliación del trabajo y los cuidados informales mediante excedencias más amplias ${ }^{57}$, o estableciendo un estatuto jurídico del cuidador informal que garantice sus necesidades y que "bien facilite la posibilidad de compatibilizar trabajo con cuidado, bien reconozca la labor del cuidador como asimilada a la del trabajo" 58 . Ahora bien, una cosa es tratar de abordar esta desventajosa que incide negativamente sobre la calidad de vida de la población cuidadora afectada, tratando de paliar algunos de sus efectos, y otra considerarlo suficiente. El objetivo final debe ser lograr que la atención a las personas en

\footnotetext{
52 Rodríguez Ruiz, B. (2010), “Hacia un Estado postpatriarcal: Feminismo y cuidadanía”, op. cit., pág. 111.

53 En España hay 278.100 personas con un empleo a tiempo parcial para poder atender a personas dependientes, una cifra de la que el 95 \%, es decir 263.900, son mujeres, frente a tan solo 14.100 hombres, el 5 \%. Vid. Submuestra de la última Encuesta de Población Activa del INE, de marzo de 2018 http://www.ine.es/prensa/epa_2017_s.pdf

${ }^{54}$ La perpetuación de roles estereotipados o sexistas ha motivado que el Tribunal Constitucional haya declarado la inconstitucionalidad de medidas aparentemente protectoras o de acción positiva (STC 317/1994, de 28 de noviembre)

${ }^{55}$ Molina Navarrete, C. (2009), "El régimen cuasi-profesional de cuidados de las personas dependientes en el entorno familiar: visualización de un trabajo con rostro de mujer”, Revista de Trabajo y Seguridad Social, 297, pág. 39.

${ }^{56}$ Numerosos estudios publicados así lo confirman y el Observatorio Estatal para la Dependencia viene denunciándolo en sus dictámenes anuales. Vid. El más reciente de 1 de marzo de 2019, número XIX en: https://www.directoressociales.com/images/Dec2019/INFO\%20GLOBAL\%20XIX\%20DICTAMEN\%20 V2-2.pdf

${ }^{57}$ Rodríguez Cabrero, G. (2007), “La protección social de la dependencia en España. Un modelo sui generis de desarrollo de los derechos sociales”, op. cit., pág. 78.

${ }^{58}$ González Ortega, S. y Navas-Parejo Alonso, M. (2009), "La protección de las situaciones de dependencia personal y el papel del cuidador no profesional, informal o familiar”, en González Ortega, S. y Carrero Domínguez, C. (coord.), El estatuto jurídico del cuidador de las personas en situación de dependencia, Madrid, Centro de Estudios Ramón Areces, págs. 17-42. Si bien advierten al mismo tiempo que a la hora de configurar tal estatuto jurídico habría que evitar incentivar la autoexclusión del mercado laboral de las mujeres, principales cuidadoras en el contexto actual.
} 
situación de dependencia sea una responsabilidad equitativamente asumida por la sociedad entre hombres y mujeres con la implicación de las instituciones públicas, puesto que el cuidado no tiene género.

No ha de perderse de vista, en todo caso, la doble perspectiva desde la que el sistema de atención debe afrontar el cuidado de las personas en situación de dependencia: asegurando la atención integral, especializada, de calidad, de las personas dependientes; pero ofreciendo, también, el suficiente apoyo a las personas cuidadoras informales o familiares, que, a día de hoy, siguen siendo el principal medio a través del cual se atiende a la dependencia. A tal fin, la LAAD establece en su artículo 18.4 que el Consejo Territorial del Sistema para la Autonomía y Atención a la Dependencia "promoverá acciones de apoyo a los cuidadores no profesionales que incorporarán programas de formación, información y medidas para atender los periodos de descanso”59.

Tras doce años de vigencia de la LAAD, puede decirse que ésta ha dotado de eficacia directa a un derecho social que no se encontraba expresamente reconocido en la Constitución, pero que sí encontraba fundamento en diversos preceptos constitucionales, como los artículos 14 y 9.2 CE (no discriminación e igualdad real y efectiva, 10.1 y 15 CE (derecho a una vida digna), 49 CE (personas con discapacidad) y 50 CE (tercera edad). Y lo hace reconociendo un nivel de protección mínimo común para todas las personas en situación de dependencia residentes en cualquier parte del territorio nacional, garantizando así la igualdad en el ejercicio de este derecho subjetivo de la ciudadanía, tal y como es reconocido. Entre sus aspectos positivos cabe añadir, además, que la LAAD ha contribuido a visibilizar la tarea de los cuidados que venía siendo desempeñada hasta ahora de manera mayoritaria por mujeres, sacando el tema del ámbito estrictamente doméstico y familiar y contribuyendo a su asunción como un asunto de responsabilidad no sólo individual sino también social en el que deben contribuir las distintas Administraciones Públicas.

No obstante, la Ley ha mostrado su mayor debilidad en lo concerniente a su financiación, que se ha visto claramente afectada con reformas que no han respetado el principio de no regresividad de las conquistas sociales y que han supuesto recortes importantes en las cuantías de las prestaciones económicas, reduciendo el nivel mínimo, suprimiendo las

\footnotetext{
59 Un análisis sobre la heterogeneidad de las medidas que las distintas Comunidades Autónomas han previsto en aplicación del artículo 18.4 LAAD puede verse en Carrizosa Prieto, E. (2009), "Las medidas autonómicas de promoción y protección de los cuidadores informales”, en González Ortega, S. y Carrero Domínguez, C. (coord.), El estatuto jurídico del cuidador de las personas en situación de dependencia, Madrid, Centro de Estudios Ramón Areces, págs. 131-161. Ante tal heterogeneidad, CARRIZOSA considera necesario uniformar ciertas medidas de protección, al menos para los casos en que la persona cuidadora informal ha de compatibilizar esta prestación con la realización de una actividad profesional.
} 
cotizaciones de las personas cuidadoras familiares, entre otros retrocesos ${ }^{60}$. Y dando lugar a que, como consecuencia de insuficiente financiación, muchas personas con una situación de discapacidad valorada y reconocida no lleguen a recibir nunca la prestación a la que tienen derecho ${ }^{61}$. Finalmente, entre los retos a afrontar, sigue estando pendiente una evaluación del impacto negativo de género que puede estar teniendo la feminización de los cuidados, como denuncia el Observatorio Estatal de la Dependencia, en la medida en que los mismos no obedecen a una libre elección y las prestaciones previstas en la LAAD para el cuidado informal o familiar pueden estar contribuyendo a perpetuarlo.

\section{RECAPITULACIÓN}

Una sociedad que propugne la dignidad humana y busque alcanzar la igualdad y libertad real y efectiva de los individuos no puede desentenderse de las personas que precisan del auxilio de otros para realizar las actividades básicas de la vida diaria. La situación de especial vulnerabilidad y necesidad que supone la dependencia ha de ser, por tanto, un asunto social, de atención prioritaria por parte del Estado.

Fundamento constitucional para garantizar el derecho a la promoción de la autonomía y al cuidado de las personas en situación de dependencia lo ofrecen el artículo 10.1 CE en conexión con el $15 \mathrm{CE}$, que garantizan una vida digna y el pleno desarrollo de la personalidad; el artículo 14 CE en conexión con el 9.2 CE, que recoge un mandato a los poderes públicos para asegurar la libertad e igualdad real y efectiva, y la participación en la vida política, económica, cultural y social; así como los artículos 49 CE y 50 CE, que reclaman la acción de los poderes públicos para amparar a las personas con discapacidad y a la tercera edad, colectivos entre los que se encuentra el mayor número de personas afectadas por una situación de dependencia.

Las personas son, por naturaleza, seres interdependientes, expuestos a lo largo de su proceso vital a situaciones de vulnerabilidad, que hacen necesario el auxilio y cuidado de otros. La dependencia, como estado permanente de personas que, por razones derivadas de la edad, la enfermedad o la discapacidad, y ligadas a la pérdida de autonomía, precisan de la ayuda de otras para realizar actividades básicas de la vida diaria, lejos de ser un problema marginal, va a seguir creciendo previsiblemente, al igual que aumenta la esperanza de vida y la supervivencia frente a enfermedades discapacitantes.

\footnotetext{
${ }^{60}$ La mayor parte de estos recortes se llevaron a cabo por la reforma de la LAAD realizada por el Real Decreto-ley 20/2012, de 13 de julio, de medidas para garantizar la estabilidad presupuestaria y de fomento de la competitividad, llevó a cabo la principal reforma de la LAAD con significativos recortes

${ }^{61}$ Durante 2018 fallecieron sin haber podido ejercer sus derechos derivados de la condición de persona en situación de dependencia 30.400 personas. Esto supone que diariamente fallecen más de 80 personas dependientes sin haber llegado a recibir prestaciones o servicios Vid. XIX Dictamen del Observatorio Estatal para la Dependencia, de 1 de marzo de 2019, pág. 1.
} 
Aunque lo deseable sería que el derecho al cuidado de las personas en situación de dependencia se garantizase expresamente en la Constitución -en una futura, aunque previsiblemente lejana, reforma constitucional-; entre tanto, su positivación como derecho subjetivo de la ciudadanía en la Ley de Promoción de la Autonomía Personal y Atención a las Personas en Situación de Dependencia (LAAD) ha permitido dotarlo de eficacia y justiciabilidad. Siquiera en desarrollo de los principios rectores contenidos en los artículos 49 y $50 \mathrm{CE}$, y con las limitadas garantías que parece dispensarle el artículo 53.3 CE, lo cierto es que la línea que separa los derechos sociales de los clásicos derechos fundamentales se hace cada vez más tenue y este derecho al cuidado puede encontrar un grado adicional de protección en conexión con los derechos fundamentales a la vida e integridad física y moral y a la igualdad y no discriminación.

La LAAD ha contribuido a que la tarea del cuidado deje de ser un asunto estrictamente doméstico o familiar, visibilizando una tarea que, hasta la fecha, ha venido siendo desempeñada de forma abrumadoramente mayoritaria por las mujeres, con el consiguiente coste para el desarrollo de su proyecto profesional y vital. En este sentido, asume la idea de que la dependencia es una responsabilidad que la sociedad debe afrontar equitativamente y en la que tienen que implicarse todas las Administraciones Públicas. Asegurando, además un mínimo nivel de garantías para todas las personas con independencia del lugar donde residan. La apuesta por un modelo orientado a priorizar las prestaciones en especie, frente a la subsidiariedad de las prestaciones económicas, hacía pensar en logros importantes desde la perspectiva de la calidad de la atención, de la creación de empleo en el sector de los cuidados o del impacto positivo de género, al sustituir al cuidado exclusivamente familiar o informal que recae sobre las mujeres. Sin embargo, la realidad en estos doce años de vigencia de la Ley ha empañado el optimismo y las expectativas generadas. La excesiva remisión al desarrollo reglamentario y el escaso respecto al principio de no regresividad en los niveles de protección alcanzados por los derechos sociales, permitirían, bajo el pretexto de la crisis económica y las exigencias del déficit, recortes sustanciales que afectaron a las cuantías de las prestaciones y a los servicios prestados. De otro lado, la opción más extendida por los cuidados informales o familiares, convirtieron la excepcionalidad de las prestaciones económicas en la regla, con la consiguiente perpetuación del rol de cuidadoras de las mujeres, normalizándolo además como un subempleo feminizado.

El comprensible deseo de las personas en situación de dependencia de recibir la atención y los cuidados necesarios en su domicilio y su entorno familiar, tan arraigado además en nuestra sociedad y cultura, debe ser tenido en cuenta. No se trata desvincular por completo el cuidado de las personas dependientes del ámbito familiar, en el que además se encuentran implicadas responsabilidades morales y éticas. Sino de modificar la tendencia discriminatoria a que ese conjunto de responsabilidades éticas y familiares recaigan sobre las mujeres. Se hace necesario, por ello, incidir -desde la educación, por supuesto, pero también en otros ámbitos como el laboral-, en que el cuidado no tiene género y que debe 
ser asumido de forma equitativa entre mujeres y hombres. Y el Estado también tiene responsabilidad en el cuidado de las personas en situación de dependencia, para garantizar, de un lado, que reciban una atención suficiente y de calidad que promueva su autonomía, y de otro, que las personas del entorno familiar en quienes recae gran parte de su atención no pierdan tampoco unas mínimas condiciones de calidad de vida en el desempeño de esta responsabilidad.

\section{BIBLIOGRAFÍA:}

Abramovich, V. y Courtis, C. (2002), Los derechos sociales como derechos exigibles, Madrid, Trotta.

Alexy, R. (2009), Derechos sociales y ponderación, Madrid, Fundación Coloquio Jurídico Europeo.

Alonso Seco, J. M. y Alemán Bracho, C. (2017), "Las prestaciones de atención a la dependencia y su consideración como derechos sociales”, Revista de Derecho Político, 100, págs. 987-1025.

BÖCKENFÖRDE, E. (1993), Escritos sobre derechos fundamentales, Nomos Verlagsgesellschaft, Baden Baden.

CARRIZOSA PRIETO, E. (2009), “Las medidas autonómicas de promoción y protección de los cuidadores informales”, en GonzÁlez OrtegA, S. y CARrero Domínguez, C. (coord.), El estatuto jurídico del cuidador de las personas en situación de dependencia, Madrid, Centro de Estudios Ramón Areces, págs. 131-161.

Cascajo Castro, J. L. (2012), "Derechos sociales”, en Cascajo Castro, J. L., et al., coord., Derechos sociales y principios rectores. Actas del IX Congreso de la Asociación de Constitucionalistas de España, Valencia, Tirant lo Blanch, págs. 17-44.

CAscajo Castro, J. L., (2009) “Los derechos sociales, hoy”, Revista catalana de dret públic, 38, págs. 21-41.

Cavas Martínez, F. (2007), Ley de dependencia: estudio de la Ley 39/2006, de 14 diciembre, sobre promoción de la autonomía personal y atención a las personas en situación de dependencia, Cizur Menor, Thomson-Aranzadi.

Escobar Roca, G. (2012) “Presupuestos de teoría dogmática y constitucional”, en EsCOBAR RocA (dir.), Derechos sociales y tutela antidiscriminatoria, Pamplona, Aranzadi, págs. 287-458.

Escobar RocA, G. (2012) “Los derechos fundamentales sociales de prestación”, en Escobar Roca (dir.), Derechos sociales y tutela antidiscriminatoria, Pamplona, Aranzadi, págs. 459-647. 
Ferrajoli, L., Moreso, J. J. y Atienza, M. (2008), La Teoría del derecho en el paradigma constitucional, Madrid, Fundación Coloquio Jurídico Europeo.

GonzÁlez ORTEGA, S. (2010), Informe sobre la Ley de promoción de la autonomía personal y atención a las personas en situación de dependencia, Madrid, Fundación Democracia y Gobierno Local.

González Ortega, S. y Navas-Parejo Alonso, M. (2009), "La protección de las situaciones de dependencia personal y el papel del cuidador no profesional, informal o familiar”, en González Ortega, S. y Carrero Domínguez, C. (coord.), El estatuto jurídico del cuidador de las personas en situación de dependencia, Madrid, Centro de Estudios Ramón Areces, págs. 17-42.

JimENA QuESADA, L. (2012): “El derecho a la autonomía de las personas con discapacidad”, en EscoBAR RocA (dir.), Derechos sociales y tutela antidiscriminatoria, Pamplona, Aranzadi, págs. 1393-1486.

Marrades Puig, A. (2016), "Los nuevos derechos sociales: el derecho al cuidado como fundamento del pacto constitucional”, Revista de Derecho Político, 97, págs. 209-242.

Martín CANo, M. C. y Ruiz Seisdedos, S. (2010), "La Ley de Dependencia: una mirada con perspectiva de género”, Documentos de Trabajo Social, 48, pág. 84-97.

MARTínez SAMPERE, E. (2014), “Ciudadanía democrática, voluntad política y estado social ”, Igualdad y Democracia: el género como categoría de análisis jurídico, Valencia, Corts Valencianes, pág. 443-452.

Molina Navarrete, C. (2007), “El régimen cuasi-profesional de cuidados de las personas dependientes en el entorno familiar: visualización de un trabajo con rostro de mujer”, Estudios Financieros. Revista de Trabajo y Seguridad Social, 297, págs. 33-78.

Monereo PÉREz, J. L. (2007), “El Modelo de protección de la dependencia: el derecho subjetivo de ciudadanía social”, Documentación Administrativa, 276-277, págs. 569-629.

Monereo PÉREz, J. L., coord. (2007), La protección jurídica de las situaciones de dependencia: estudio sistemático de la Ley 39/2006, de 14 de diciembre, de promoción de la autonomía personal y atención a las personas en situación de dependencia, Granada, Comares.

Montoya Melgar, A., dir. (2007), La protección de las personas dependientes: comentario a la Ley 39/2006, de promoción de la autonomía personal y atención a las personas en situación de dependencia, Cizur Menor, Thomson-Civitas.

PisARello, G. (2007), Los derechos sociales y sus garantías, Madrid, Trotta.

REVEnga SÁNCHEZ, M. (2009) "Los derechos sociales (instrumentos de garantía en la Constitución Española)”, Revista Parlamentaria de la Asamblea de Madrid, 21, págs. 97106. 
RodríGUez CABRERO, G. (2007), "La protección social de la dependencia en España. Un modelo sui generis de desarrollo de los derechos sociales”, Política y Sociedad, 44, 2, págs. 69-85.

RoDRíGUEz RuIZ, B. (2010), “Hacia un Estado postpatriarcal: Feminismo y cuidadanía”, Revista de Estudios Políticos, 149, págs. 87-122.

SAlCEDo BeltrÁn, C. (2016), "La aplicabilidad directa de la Carta Social Europea por los órganos judiciales”, Trabajo y derecho: nueva revista de actualidad y relaciones laborales, 13, págs. 27-52.

Sempere NAVArro, A. V., dir. (2008), Comentario sistemático de la Ley de la dependencia: Ley 39/2006, de 14 de diciembre, de promoción de la autonomía personal y atención a las personas en situación de dependencia y normas autonómicas, Cizur Menor, Thomson- Aranzadi.

TEnorio SÁnchez, P. (2014), “El Tribunal Constitucional, la cláusula del estado social y los derechos sociales”, en Terol Becerra, M., Jimena QuesAdA, L. (dir.) Tratado sobre Protección de Derechos Sociales, Valencia, Tirant lo Blanch, págs. 125-142.

Terol Becerra, M. (2012), "Treinta años de desarrollo constitucional y legislativo de los derechos sociales: derechos ciudadanos y principios rectores”, Derechos sociales y principios rectores. Actas del IX Congreso de la Asociación de Constitucionalistas de España, Valencia, Tirant lo Blanch, págs. 45-86.

VAN HoOF, G. (1984), “The legal nature of economic, social and cultural rights: A rebuttal of some traditional views”, en Alston, P. y TOMASEVski, K., The Right to Food, Utrecht. 